\title{
Tuberculin Skin Test, Chest Radiography and Contact Screening in Children <5 Y: Relevance in Revised National Tuberculosis Control Programme (RNTCP): Author's Reply
}

\author{
Sandhya Chauhan
}

Received: 20 May 2013 / Accepted: 3 July 2013 / Published online: 16 August 2013

(C) Dr. K C Chaudhuri Foundation 2013

To the Editor: We fully agree with the authors that there are many issues with relevance to $\mathrm{INH}$ chemoprophylaxis in latent TB infection [1]. INH chemoprophylaxis is definitely relevant in latent $\mathrm{TB}$ infection (LTBI), provided all the mentioned factors along with the age related patterns pertaining to relevant disease are taken into consideration.

Mantoux positivity in infants cannot be ignored in the absence of sputum positive index case. Positive Mantoux test represents recent primary infection and below $2 \mathrm{y}$ of age, it represents the greatest risk of disease progression to miliary disease or TBM, without significant prior symptoms [2]. Moreover, positive Mantoux itself is a criterion for defining relevant disease in children aged $<2 \mathrm{y}$ and this necessitates appropriate treatment in these children. Therefore, administering INH chemoprophylaxis in such children might lead to under treatment, especially in presence of radiological evidence of the infection.

In the present era of dual threat from HIV and drug resistant $\mathrm{TB}$, several changes have been observed in the epidemiology of TB [3]. In such a scenario, LTBI in older age groups cannot be left without intervention irrespective of their contact status. Though infected children aged 2-10 y rarely develop serious disease, majority of children in high

\footnotetext{
S. Chauhan

Department of Pediatrics,

Sri Ram Murti Smarak Institute of Medical Sciences,

Bareilly, Uttar Pradesh, India

S. Chauhan $(\bowtie)$

69, Silver Estate, Bareilly 243006, Uttar Pradesh, India

e-mail: drsandhyapedia@gmail.com
}

prevalent communities like India are infected during this period. This results in a significant burden of disease. Any significant immune compromise occurring in even a small proportion of such children would result in poor disease containment and progression to significant disease in a substantial population [2]. This will eventually lead to failure of whatever control we are trying to achieve over TB.

Instead of Mantoux positivity or history of contact, presence or absence of relevant symptoms form the criteria for defining relevant disease in $2-10 \mathrm{y}$ age group. Further, there is a relatively lower risk of disease progression in this age group. Hence may be we are justified in not giving chemoprophylaxis to well nourished and asymptomatic Mantoux positive children, provided they are kept under regular follow up and monitored for development of clinical symptoms or weight loss.

Finally, the issue of intervention in childhood LTBI can be solved to a great extent if the screening guidelines are followed diligently and a regular follow up of relevant groups is ensured.

\section{References}

1. Chauhan S, Gahalaut P, Rathi AK. Tuberculin skin test, chest radiography and contact screening in children $\leq 5 \mathrm{y}$ : Relevance in Revised National Tuberculosis Control Programme (RNTCP). Indian J Pediatr. 2013;80:276-80.

2. Marais BJ, Gie RP, Schaaf HS, Hesseling AC, Obihara CC, Starke $\mathrm{JJ}$, et al. The natural history of childhood intra-thoracic tuberculosis: A critical review of literature from the pre-chemotherapy era. Int $\mathrm{J}$ Tuberc Lung Dis. 2004;8:392-402.

3. Mukherjee A, Lodha R, Kabra SK. Changing trends in childhood tuberculosis. Indian J Pediatr. 2011;78:328-33. 